\title{
Learner Perceptions of a Video Recording Activity for Patient Consultation Training in a Pharmacist-Led Primary Care Clinic Located in an Academic Institution
}

\author{
Hayley Hefford, BSc, PharmD; Anita I. Kapanen, MSc, PhD; Nic Medgyesi, BSc, PharmD; Jamie Yuen, BSc(Pharm)
}

Faculty of Pharmaceutical Sciences, The University of British Columbia, Vancouver, BC, Canada

\begin{abstract}
Description of the problem: Development of evidence-based educational activities is needed to provide educators with the tools to aid learners in strengthening patient consultation skills in the primary care practice setting, an emerging area of practice in Canada.

Objective: The objective was to develop an educational activity to bring self-awareness to fourth year pharmacy student and pharmacy resident consultation skills and to determine learner perceptions of this educational activity, including identifying the key areas of skill development that learners found were positively impacted.

Description of the innovation: An innovative learning activity utilizing audio-video technology to enable recording and reviewing of learner-led patient consultations was developed and implemented within the University of British Columbia Pharmacists Clinic. Learners had the opportunity to lead 60-minute patient consultations. With patient and learner consent, patient consultations were recorded for learner viewing and self-assessment. Pharmacist preceptors supervised and assessed learner performance. Learners completed an online anonymous survey after the learning activity to evaluate its value.

Critical analysis: Between September 2018 and July 2019, eight pharmacy learners, consisting of student pharmacists (5) and postgraduate pharmacy residents (3) completed the learning activity and provided their feedback. The majority of learners (87.5\%) felt the learning activity was beneficial to the development of patient consultation skills. Learners gained awareness of areas requiring improvement which included appropriate questioning, clear and concise language, time management and non-verbal habits.

Next steps: Adapting and modifying this learning activity to align with specific practice settings and learning objectives is feasible for other primary care practice sites offering experiential practicums.
\end{abstract}

Keywords: video; recording; primary care; student; self-assessment

\section{Description of the Problem}

Studies have demonstrated that patient-centered communication results in patient satisfaction, positive impacts on patient health, and improved patient adherence. ${ }^{1}$ Association of Faculties of Pharmacy of Canada (AFPC) Educational Outcomes guide the educational development of pharmacy learners to ensure they are equipped with the skills required to become competent pharmacists. ${ }^{2}$ Each section of the AFPC Educational Outcomes describes attributes of communication and pharmacist-patient consultation, among other aspects of pharmacy practice. ${ }^{2}$

Pharmacy programs routinely utilize video-recorded peer and standardized patient consultation activities for interviewing and communication skills training. ${ }^{3}$ Many of these activities are shown to be effective, particularly when integrating both self-assessment and preceptor assessment during activities such as medication counselling. ${ }^{4,5}$ Although they are helpful for preparing students to perform patient consultations in community and hospital settings, there are limitations in the application to primary care practice, where consultations tend to be longer in duration, complex medication related issues of differing levels of acuity exist, and numerous follow-up

Corresponding author: Jamie Yuen, BSc(Pharm)

Faculty of Pharmaceutical Sciences

The University of British Columbia

2405 Wesbrook Mall, Vancouver, BC, Canada, V6T 1 Z3

Phone: 1 (604) 827-0704; Email: jamieh.yuen@ubc.ca appointments are often required. Further, there is limited existing literature evaluating the use of audio-video (AV) technology to train pharmacy residents in primary care practice. ${ }^{6}$ With the current efforts to expand pharmacists into team-based primary care in Canada and internationally, pharmacists must be prepared to provide thorough patientcentered consultations, which will require the development of evidence-based training activities specific to primary care settings. ${ }^{7}$

The objective was to develop an educational activity to bring self-awareness to fourth year pharmacy student and pharmacy resident communication and consultation skills and to determine learner perceptions of this educational activity, including identifying the key areas of skill development that learners found were positively impacted.

\section{Description of the Innovation}

AV technology was used to enable recording and reviewing of learner-led patient consultations and implemented within the University of British Columbia (UBC) Pharmacists Clinic (the Clinic). The Clinic is a university-affiliated, pharmacist-led patient care clinic and a practice site for learners to complete experiential education. This faculty-run clinic is an experiential education site for fourth-year student pharmacists and a clinical rotation site for residents completing hospital and community residencies (collectively referred to as learners in this article). Rotations at the Clinic last four to eight weeks and serve as an opportunity for learners to understand and apply the 
Comprehensive Medication Management (CMM) approach to patient care, which is the current standard for pharmacist consultation in the Clinic. Initial consultations and follow-up appointments are scheduled for 60 minutes and 30 minutes in length, respectively. The Clinic is equipped with AV technology via a discreet camera and microphone installed in each consultation room, which enables patient consultations to be observed by preceptors in real-time and recorded for learners to review at a later time.

This learning activity is innovative in that learners have the opportunity to lead 60-minute consultations with real patients, within a primary care setting. This differs from most literature which mainly consists of learners counselling standardized or simulated patients in a learning environment, often restricted to much less than 60 -minutes. ${ }^{3,8}$ In this practice setting, there is a variable amount information known about the patient prior to the initial consultation depending on referral notes and provincial prescription records and therefore, learners are tasked with gathering pertinent information and providing recommendations by the end of the encounter. They must also build rapport and trust with patients over a 60-minute appointment when assessing complex chronic conditions, in contrast to brief routine medication counselling scenarios that is described in much of the literature.

The practice site had four pharmacist preceptors during the time of the study and each student was designated one primary preceptor, but the three co-preceptors may have been the supervising pharmacist for the learning activity based on scheduling and availability. Each pharmacist preceptor had completed standardized practice educator training through the school's experiential education department and received internal training on interpreting and completing the assessment forms based on their assessment and clinical judgement. Pharmacist preceptors spent approximately 60 minutes observing each learner-led patient appointment. Assessment forms took about 10-15 minutes to complete. Approximately 30 minutes was spent debriefing with each learner and reviewing the different aspects of the assessment form.

All learners completing a practicum at the Clinic from September 2018 to July 2019 were invited to participate in the assessment of the learning activity and written informed consent was given prior to the recording. Patients provided their informed consent to being recorded and having a learner facilitate their consultation. The learning activity was implemented once the primary preceptor determined the learner had sufficient competency to lead an appointment, identify and address drug therapy problems. A licensed pharmacist preceptor supervised the 60-minute consultation through the AV system and completed the same assessment form as the student. Self-assessment forms were developed based on the CMM approach, AFPC Educational Outcomes and the Clinic's internal quality assurance initiative for their clinicians. ${ }^{2}$ On the assessment forms, scores of "fully complete" (FC), "partially complete" (PC), or "not applicable" (N/A) were given in each category based on the professional judgement of the supervising pharmacist. Following the consultation, the preceptor immediately completed the assessment. The learners completed the assessment form immediately following consultation (prior to watching the recording) and after viewing the recording (within 48 hours of the patient consultation) without debriefing with the pharmacist. This process was completed within 48 hours of their patient consultation as the recording took several hours to become available. The supervising pharmacist and learner then discussed their assessments within 72 hours of the patient consultation.

An anonymous online feedback survey, created based on available literature, regarding the value of the learning activity was placed on Qualtrics ${ }^{\mathrm{TM}}$ survey tool (Qualtrics, Drive Provo, Utah, US) hosted on UBC's server, which the learners responded to within 48 hours following completion of the learning activity. ${ }^{3-5}$ This included both Likert-style questions (Table 1) and three open-ended questions assessing areas of the activity that were difficult, beneficial to learning and not beneficial to learning. Content analysis of open-ended text responses was performed by two coders (HB, NM) independently to determine themes, after which the team (all authors) discussed the findings and agreed on the themes. Microsoft Word software version 16.36 and Microsoft Excel software version 16.39 (Seattle, WA, US) were used to manage the data. Assessment forms and feedback surveys were anonymized prior to analysis for this study. The study procedures were reviewed and approved by UBC's Behavioural Research Ethics Board (H18-02229).

\section{Critical Analysis}

Between September 2018 to July 2019, eight out of ten learners on their practicums completed the activity. Five (62.5\%) were fourth year Entry-to-Practice Doctor of Pharmacy students, two (25\%) were pharmacists completing a post-graduate community residency and one (12.5\%) was a pharmacist completing a post-graduate accredited hospital residency. Likert-style statement results from the online feedback survey are summarized by response frequency in Table 1 . The majority of learners (87.5\%) agree that reviewing a video recording of themselves helped reinforce self-awareness of their own competencies, identify areas requiring improvement in verbal and non-verbal communication and identify areas requiring improvement on the systematic approach of their consultation process. All learners felt the preceptor's involvement with supervision, completing an assessment and debriefing with them was beneficial. The majority of learners (87.5\%) agree that the learning activity was beneficial to the development of their patient consultation skills, a good use of their time and a technique they would like to use again in the future or recommend to others. 
Learner responses to the open-ended questions on the feedback survey and self-assessment form identified areas they improved as a result of this activity, as well as areas that they identified as requiring improvement. These responses were analyzed and determined to fit into the four following themes; appropriate questioning, clear and concise language, timemanagement, and non-verbal habits. Select quotes from the online survey that support the themes identified can be found in Table 2. In addition, the majority of learners did not express any major aspects that were difficult or not beneficial to their learning. Two learners would have preferred to implement the learning activity earlier in their rotation, which would have provided the opportunity to apply the feedback to subsequent patient consultations.

Table 1. Responses to the online feedback survey Likert-style questions $(n=8)$

\begin{tabular}{|c|c|c|c|c|c|}
\hline & $\begin{array}{l}\text { Strongly } \\
\text { Agree }\end{array}$ & $\begin{array}{c}\text { Somewhat } \\
\text { Agree }\end{array}$ & $\begin{array}{l}\text { Neither } \\
\text { Agree or } \\
\text { Disagree }\end{array}$ & $\begin{array}{l}\text { Somewhat } \\
\text { Disagree }\end{array}$ & $\begin{array}{l}\text { Strongly } \\
\text { Disagree }\end{array}$ \\
\hline $\begin{array}{l}\text { Overall, reviewing a video recording of } \\
\text { myself was beneficial to the } \\
\text { development of my patient- } \\
\text { consultation skills }\end{array}$ & $2(25 \%)$ & $5(62.5 \%)$ & $1(12.5 \%)$ & 0 & 0 \\
\hline $\begin{array}{l}\text { Reviewing the video recording helped } \\
\text { reinforce my self-awareness of my own } \\
\text { competencies }\end{array}$ & $2(25 \%)$ & $5(62.5 \%)$ & $1(12.5 \%)$ & 0 & 0 \\
\hline $\begin{array}{l}\text { Reviewing the video recording helped } \\
\text { me identify areas where I could } \\
\text { improve with my verbal communication }\end{array}$ & $2(25 \%)$ & $5(62.5 \%)$ & $1(12.5 \%)$ & 0 & 0 \\
\hline $\begin{array}{l}\text { Reviewing the video recording helped } \\
\text { me identify areas where I could } \\
\text { improve my non-verbal communication }\end{array}$ & $2(25 \%)$ & $5(62.5 \%)$ & $1(12.5 \%)$ & 0 & 0 \\
\hline $\begin{array}{l}\text { Reviewing the video recording helped } \\
\text { me identify areas where I could } \\
\text { improve on the systematic approach of } \\
\text { my consultation process }\end{array}$ & $4(50 \%)$ & $3(37.5 \%)$ & $1(12.5 \%)$ & 0 & 0 \\
\hline $\begin{array}{l}\text { Having my preceptor supervise and } \\
\text { complete an assessment was beneficial }\end{array}$ & $3(37.5 \%)$ & $5(62.5 \%)$ & 0 & 0 & 0 \\
\hline This activity was a good use of my time & $4(50 \%)$ & $3(37.5 \%)$ & 0 & $1(12.5 \%)$ & 0 \\
\hline $\begin{array}{l}\text { Reviewing my video recording is a } \\
\text { technique I would like to use again in } \\
\text { the future or would recommend to } \\
\text { others as a learning tool }\end{array}$ & $2(25 \%)$ & $5(62.5 \%)$ & 0 & $1(12.5 \%)$ & 0 \\
\hline
\end{tabular}


Table 2. Online feedback survey themes and supporting quotes

\begin{tabular}{|c|c|}
\hline Themes & Supporting quotes \\
\hline \multirow[t]{2}{*}{ Appropriate questioning } & $\begin{array}{l}\text { "I can also ask questions in a more open-ended manner to allow the patient } \\
\text { time to respond." }\end{array}$ \\
\hline & $\begin{array}{l}\text { "the main point of improvement that I identified was to ask some closed } \\
\text { ended questions to target specific areas that needed attention" }\end{array}$ \\
\hline \multirow[t]{3}{*}{ Clear and concise language } & $\begin{array}{l}\text { "...It also allowed me to notice opportunities for improvement in the way I ask } \\
\text { open-ended questions." }\end{array}$ \\
\hline & $\begin{array}{l}\text { "For verbal communication specifically, I noticed that some of my } \\
\text { explanations can be overwhelming information wise and to improve, I should } \\
\text { be more aware of what I am about to say before I speak so the information } \\
\text { comes across more clear and concise." }\end{array}$ \\
\hline & $\begin{array}{l}\text { "I can also use less "ums" or "likes" when gathering my thoughts to speak } \\
\text { with the patient." }\end{array}$ \\
\hline \multirow[t]{2}{*}{ Time management } & $\begin{array}{l}\text { "Reviewing the recording helped to reinforce the need to manage time more } \\
\text { appropriately and conduct the consultation in a more structured way." }\end{array}$ \\
\hline & $\begin{array}{l}\text { "I learned that I can be more organized and timely in my patient } \\
\text { consultations." }\end{array}$ \\
\hline \multirow[t]{2}{*}{ Non-verbal habits } & $\begin{array}{l}\text { "I noticed that I tend to fidget quite a bit with my hands as well as moving } \\
\text { around in my chair quite a bit. This is just an old habit for me, but to patients } \\
\text { could come across as nervousness." }\end{array}$ \\
\hline & $\begin{array}{l}\text { "Learned to be more mindful of how I present myself to the patient verbally } \\
\text { and non-verbally" }\end{array}$ \\
\hline
\end{tabular}

Pooling the data from the eight participants, before watching their recordings, learners marked themselves lower than the preceptors for $26 \%$ of the performance statements and higher than preceptors for $2.5 \%$ of the statements. After watching their recordings, $22 \%$ of the learners' self-assessment scores were lower than the preceptors' assessments while $3 \%$ were higher. Every student had at least one difference in their selfassessment pre- and post-video watching with an average of three differences. Overall, the number of self-assessed performance statements scores that increased or decreased after watching the videos were 12 and 7 , respectively. Finally, when looking at changes across the entire assessment form, after video watching $37.5 \%$ of learners' self-assessment scores were closer to resembling their supervisors' scores of them. However, post-review, half of the learners scores were less similar to their supervisor's scores of them.

These results suggest that learners found this activity beneficial to the development of their patient-consultation skills in the primary care setting. With regard to communication, it seems this activity helped to reinforce learner self-awareness of their own competencies and helped to identify areas where they could improve both their verbal and non-verbal communication. This reflects existing literature which demonstrates through quantitative results that video recording of pharmacy student interactions with standardized patients or peers helps develop key communication skills. ${ }^{9}$ The authors did not identify existing literature evaluating the usefulness of video review in pharmacy residents, which suggests the need for additional research in this particular group.

The study is limited by the small number of participants. This led to the pooling of data from all learners despite their differences in education and competency levels. Despite standardized preceptor training from the experiential education department, having different preceptors participate in this activity may have led to differences in learner and preceptor assessment. In addition, investigators were not able to implement the activity more than once due to: patient consent, the time taken for students to become sufficiently competent and the complexities of both patient and preceptor schedules. 


\section{Next Steps}

To further improve the experience and impact, this activity could be implemented both early and late in the practicum to determine if there are improvements in communication and consultation skills. Identifying appropriate patient cases to match the competency levels of the learner would enhance the experience as the difficulty level should be challenging, yet achievable. As learners generally scored themselves lower than the preceptor in this study, dedicating time to discuss the differences in assessment may impact the self-assessment and self-reflection process for learners. ${ }^{10}$ Ensuring preceptors' consistency in rating may allow for an improved experience and data collection process.

As pharmacy students and residents have different levels of competency, the activity and assessment forms can be adapted to align with the learning objectives and goals of the clinical rotation. For example, the assessment form for a pharmacy student could assess whether they identified all major drug therapy problems, while an assessment form for a pharmacy resident could assess whether they identified and addressed all major drug therapy problems. Adapting or creating an assessment form that reflects the clinical competencies and logical flow specific to the practice setting may be helpful. For example, if a clinic follows the Medication Therapy Management approach to patient care, the assessment form should be adapted to match that same structure for ease of marking. It may also be beneficial to expand the scoring system to a 5-point scale to better allow the assessment of differences in performance level. Further, learners' perceived change in confidence in patient consultation skills could also be assessed.

This innovative learning activity using video review was beneficial to patient consultation skill development in the primary care setting. Primary care practice sites may consider adopting a similar, modified approach for experiential practicums.

Conflicts of Interest: None

Funding/support: None

\section{References}

1. De Young M. Research on the effects of pharmacistpatient communication in institutions and ambulatory care sites, 1969-1994. Am J Health Syst Pharm. 1996;53(11):1277-1291. doi:10.1093/ajhp/53.11.1277

2. Association of Faculties of Pharmacy in Canada (AFPC) educational outcomes for first professional degree programs in pharmacy in Canada 2017. June 2017. Accessed August 2, 2019. https://www.afpc.info/system/files/public/AFPCEducational Outcomes 2017_final Jun2017.pdf.

3. Volino LR, Das RP. Video review in self-assessment of pharmacy students' communication skills. J Educ Learn. 2014;3(4):26-36. doi:10.5539/jel.v3n4p26

4. Zick A, Granieri M, Makoul G. First-year medical students' assessment of their own communication skills: a video-based, open-ended approach. Patient Educ Couns. 2007;68(2):161-166. doi:10.1016/j.pec.2007.05.018

5. Hammoud MM, Morgan HK, Edwards ME, Lyon JA, White $C$. Is video review of patient encounters an effective tool for medical student learning? A review of the literature. Adv Med Educ Pract. 2012;3:19-30. doi:10.2147/AMEP.S20219

6. Hazen A, de Groot E, de Gier H, Damoiseaux R, Zwart $D$, Leendertse A. Design of a 15-month interprofessional workplace learning program to expand the added value of clinical pharmacists in primary care. Curr Pharm Teach Learn. 2018;10(5):618-626. doi:10.1016/j.cptl.2018.01.006

7. Dolovich L, Pottie K, Kaczorowski J, et al. Integrating family medicine and pharmacy to advance primary care therapeutics. Clin Pharmacol Ther. 2008;83(6):913-917. doi:10.1038/clpt.2008.29

8. Hanya M, Yonei H, Kurono S, Kamei H. Development of reflective thinking in pharmacy students to improve their communication with patients through a process of role-playing, video reviews, and transcript creation. Curr Pharm Teach Learn. 2014;6(1):122-129. doi:10.1016/j.cptl.2013.09.009

9. Mort JR, Hansen DJ. First-year pharmacy students' self-assessment of communication skills and the impact of video review. Am J Pharm Educ. 2010;74(5):78. doi:10.5688/aj740578

10. Austin Z, Gregory PA. Evaluating the accuracy of pharmacy students' self-assessment skills. Am J Pharm Educ. 2007;71(5):89. doi:10.5688/aj710589 